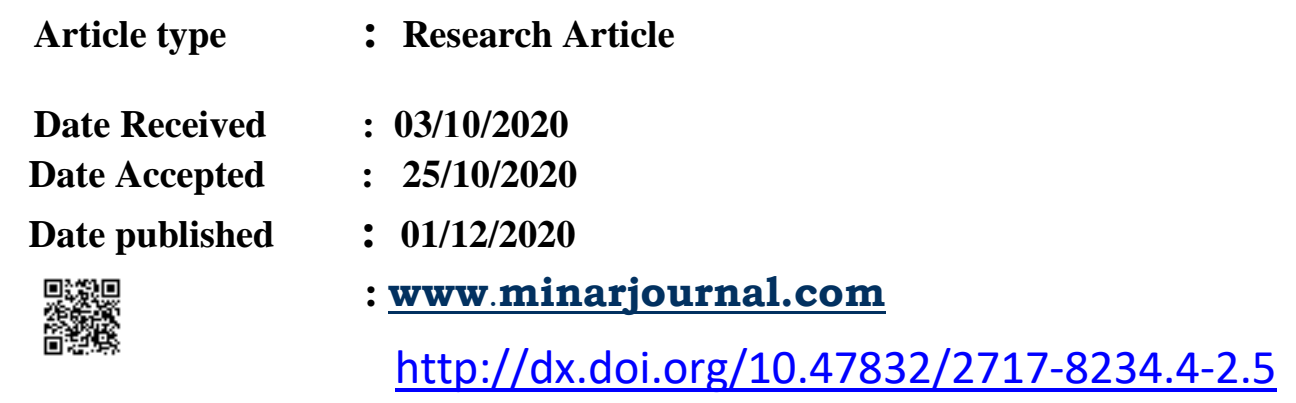

\title{
FABRICATION OF AG SB (SXSE1-X)2 /SI HETEROJUNCTION FOR SOLAR CELL APPLICATION
}

\section{Hiba H.ISSA 1}

\begin{abstract}
The preparation of the AgSb (SxSe1-x)2 was done by the quenching method. It is a quaternary substance with sulfur. Preparation of AgSb (SxSe1-x)2 thin films with sulfur was done on the glass substrate at room temperature $303 \mathrm{~K}$ with a pressure vacuum of $(0.01)$ bar by using a technique called pulsed laser deposition at thickness ( 100 nanometres). The structural properties of alloys thin films are tested by $x$-ray diffraction analysis. Our findings showed that all compounds have polycrystalline structure with cubic phase due to the deposition of the AgSb (SxSe1-x)2. The atomic force microscopy is used for showing mean size, wherever mean size decreases, and the roughness becomes more irregularity with the increase of sulphur level in the alloys. The electrical measurements of AgSb (SxSe1-x)2 /p-Si and AgSb (SxSe1-x)2/n-Si heterojunctions which is included I-V properties cell area structures of $(0.61) \mathrm{cm} 2$ were measured. The AgSb (SxSe1-x)2/n-Si showed the best results with a maximum open voltage Voc of these heterojunctions with Sulfur level $x=0.4$ ). It was most suitable for solar cell high efficiency $(\eta=0.07 \%)$ at $x=0.4$ on $n-$ Si substrate.
\end{abstract}

Keywords: Ag Sb, Quenching Method, Cell Application.

\footnotetext{
${ }^{1}$ Baghdad University, Iraq, hiba.h@sc.uobaghdad.edu.iq, https://orcid.org/0000-0001-6100-6383
}

This article has been scanned by iThenticat No plagiarism detected

Copyright @ Published by Minar Journal, www.minarjournal.com

Rimar Academy, Fatih, Istanbul, 34093 Turkey

All rights reserved 


\section{Introduction}

AgSbSe2 and its alloys stand out to be promising candidates for solar cell applications, due to their optical absorption coefficient of $104 \mathrm{~cm}-1$ with a bandgap of $0.9-1.1 \mathrm{eV}[1,2]$. Our group has reported the preparation of $\mathrm{AgSb}(\mathrm{S} x \mathrm{Se} 1-\mathrm{x}) 2$ thin films by pulsed laser deposition[4]. Photovoltaic PV structures with more than $2 \%$ efficiency have been reported [2] using such thin films as an absorber, leaving a question of intense investigation to explore this material's full potential for solar cell applications. According to the previous results we have utilized a PLD process to develop better processing of $\mathrm{AgSb}(\mathrm{S} \times \mathrm{Se} 1-\mathrm{x}) 2$ thin films and thus to improve the PV device parameters. In this paper, we report the preparation of $\mathrm{AgSb}(\mathrm{SxSe1-x}) 2$ thin films by pulsed laser deposition method on different substrates like glass and silicon wafer at room temperature. The structure, morphology, and optical properties of the films were determined using an X-ray diffractometer (XRD), Atomic Force Microscope (AFM), UV-Vis-NIR spectrophotometer. Further, these thin films were incorporated into photovoltaic structures as a window layer deposited on single-costal silicon. The effects of composition (the ratio of Se to S) on the photovoltaic PV performance were studied.

\section{Experiment Details}

Sulfur, selenium, tin, and silver are provided from Fluca, Germany a company at based on their atomic weight ratio at (the diameter was (8) $\mathrm{mm}$ and the length was $(25) \mathrm{cm})$ at $(\sim 10-5$ Torr) and sealed ampoule then heating to temperature (1273)K for five hours and then cooling to RT. The glass slides were cleaned in order to removed the contamination like oil, dust, grease, and oxides. Placing the glass slides in a sterile beaker filled with ethanol and water then drying of the glass slides by a blower. Preparation of the thin films was done by pulsed lased deposition technique as a list in Fig.1 at a negative pressure (10-3 Torr), while the deposition process is done by using the Nd:YAG,Q-switching laser beam that getting from the window at an angle of $45^{\circ}$. The laser wavelength is $(1064 / 532)$ nanometre, Laser model: Q-switched Nd: YAG Laser (SHG). The pulse width was (10) and Pulse energy was (100-1000) mJ while the frequencies were (1, 2, 3, 4, 5 and 6) $\mathrm{Hz}$. The cooling method is included the circulation of the water to remove the heat and the voltage was $(220) \mathrm{V}$. The placing of the substrate was in front of the target parallel to the target. Present between the target and the substrate is a sufficient gap, as the substrate holder doesn't form obstruction of the laser beam. Using the XRD was done for the test of the structures. Also using the $x$-ray diffractometer type (Miniflex II), with Cu-Ka x-ray tube $(\lambda=1.54055 \AA$ ). Atomic force microscopy has formed the morphology. Two kinds of measurements applied in the experiments: Pulsed Laser Deposition used for the preparation of $\mathrm{AgSb}(\mathrm{SxSe1-x}) 2$ bulk and thin films on different substrate single crystal Silicon wafers Si (n and $p$-types) for different $S$ contents $(x=0.2$ and 0.4$)$. Silicon single crystal wafers $n$-type and $p$-type substrates with crystal directions (111), were cleaned by an etching process which is shown as [3]:

1. Si wafers put in the chemical solution formed from (1) ml HF, (3) ml H NO3 for (60-180) seconds.

2. The samples were rinsed several times in distilled water.

3. Drying of the samples by soft paper.

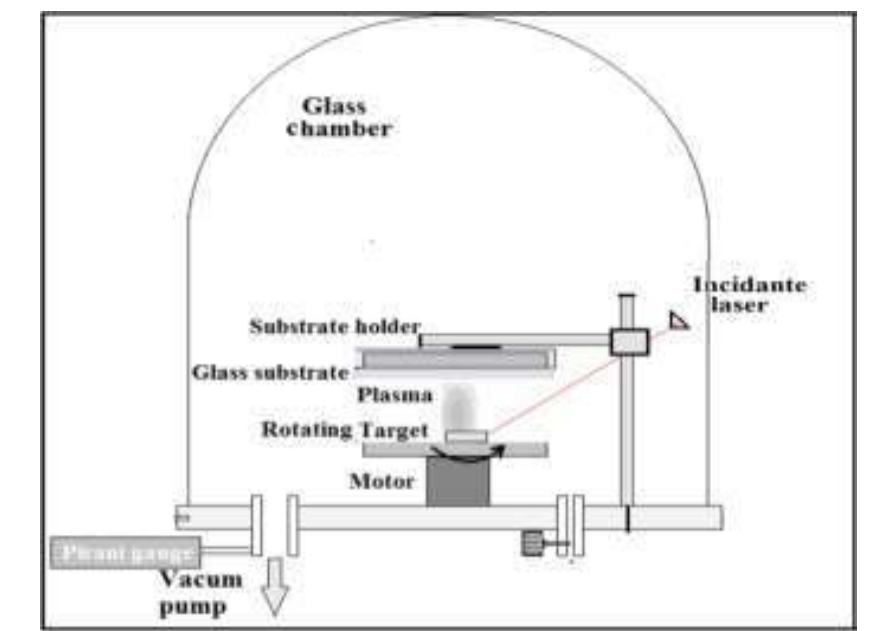

Figure.1 Schematic diagram illustrating of pulse laser deposition set up[5]

December 2020, Volume 2, Issue 4

p. $48-56$ 


\section{Results and Discussion:}

Preparation of the diffraction types of $x$-ray of $\mathrm{AgSb}(\mathrm{SxSe1-x}) 2$ that have a different composition as shown in Fig.2. There are many peaks at $2 \theta=26.87 \mathrm{o}, 31.15 \mathrm{o}, 44.53 \mathrm{o}, 52.73 \mathrm{o}, 55.32 \mathrm{o}$ and $64.77 \mathrm{o}$ indexes by (111), (200), (220), (311), (222)) and (400) planes corresponding and that prevent the production of the quaternary system.

Furthermore, the diffraction peaks present in the alloy as marked in the figure. The densities decrease with increasing the $x$ content as Fig.2, but the crystal size increased firstly, but in the end, it decreases with increasing the sulfur content.

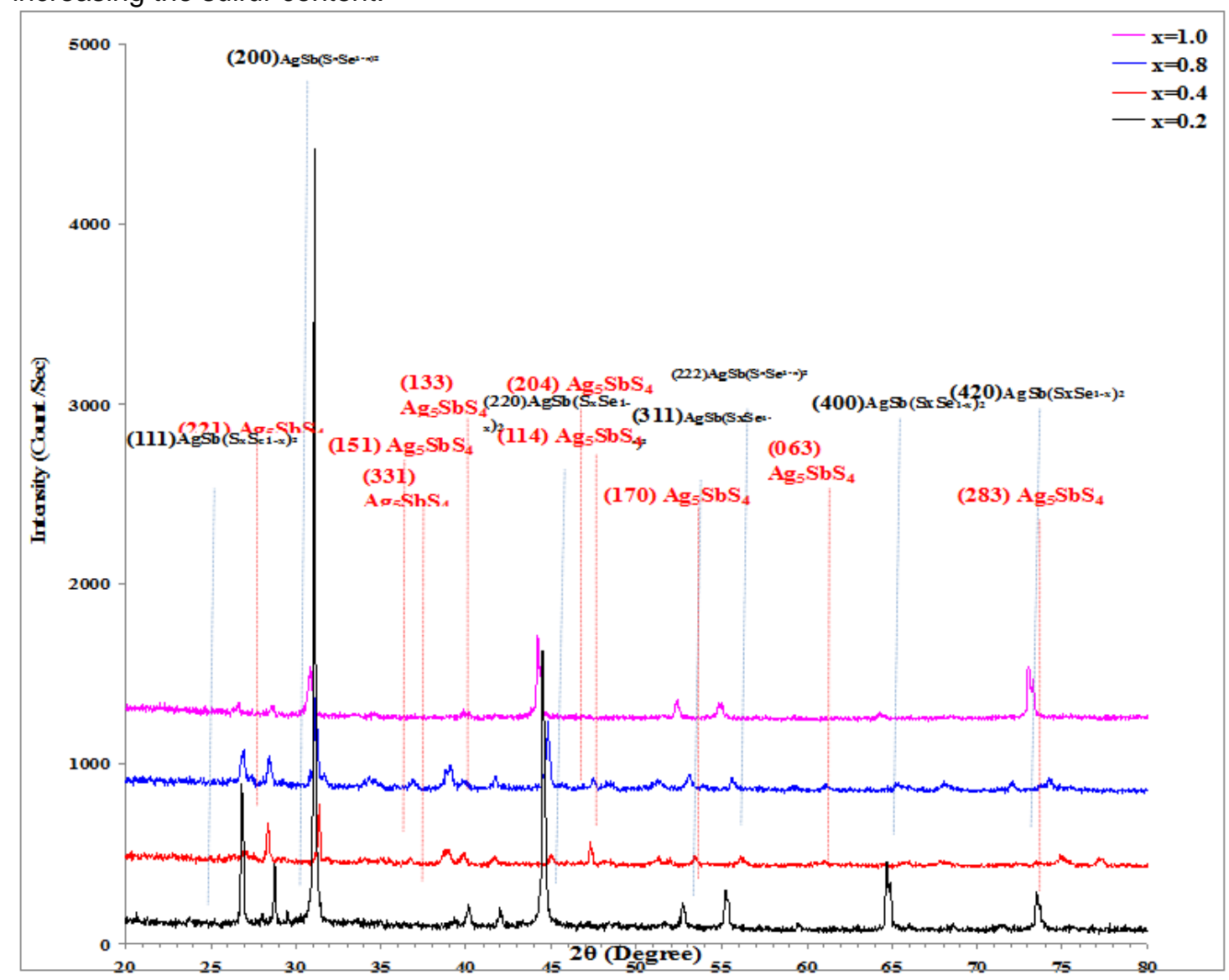

Figure.2: XRD pattern of $\mathrm{AgSb}(\mathrm{SxSe1-x}) 2$ powders with many sulfur levels[4].

Fig.3 revealed the diffraction types of X-ray for $\mathrm{AgSb}(\mathrm{SxSe} 1-\mathrm{x}) 2$ films with different $x$ content $(0.2,0.4,0.8,1)$. There is no diffraction peaks indicate the amorphous structures of the prepared samples and that agreement with [4]. The amorphous structure depended on the low thickness of the thin films at the thickness (150) nanometer. Also, when the thickness is increased, the structure will be changed to polycrystalline. 


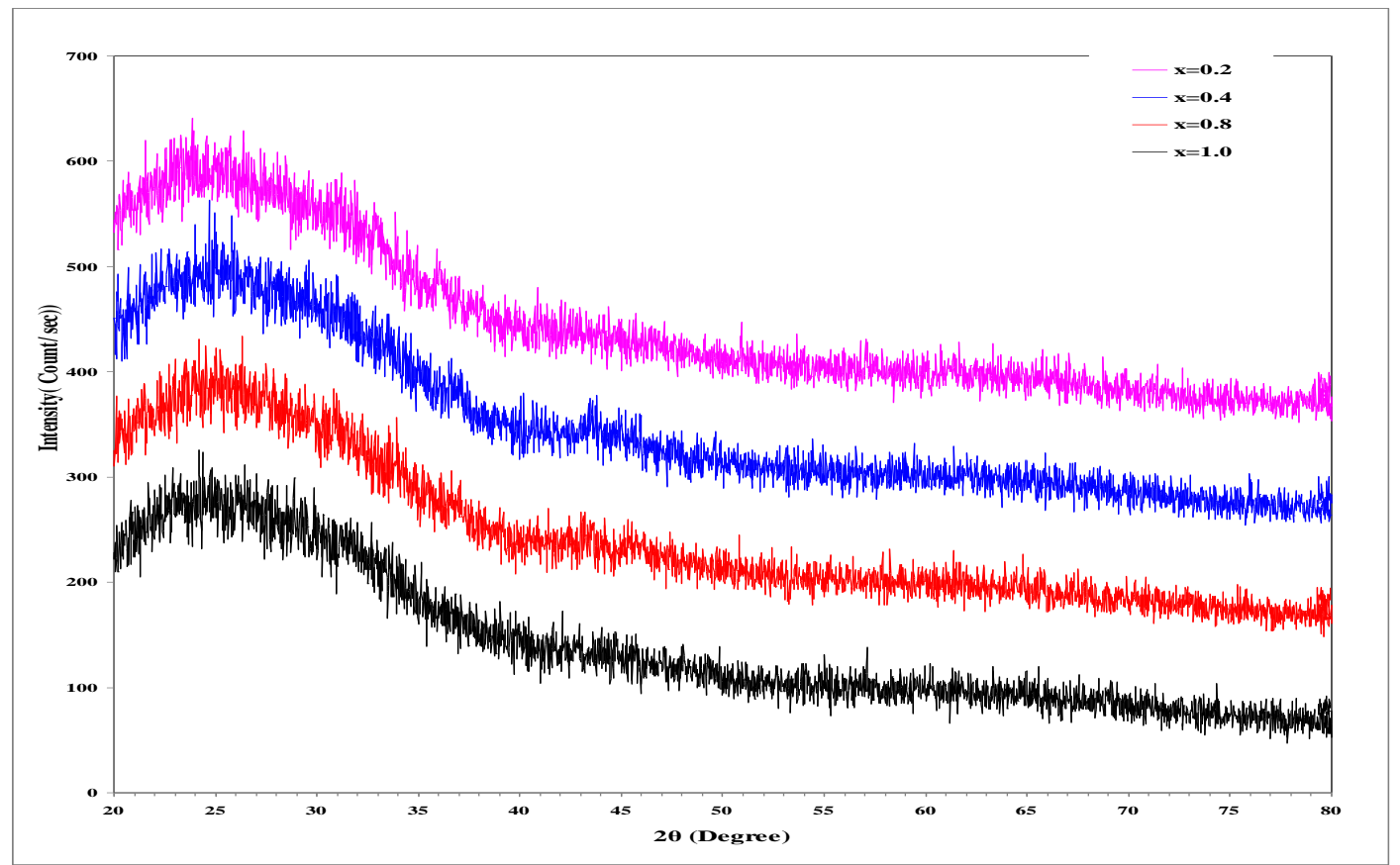

Figure.3 : XRD pattern of PLD AgSb(SxSe1-x)2 with many sulfur concentration[4]

Figure (4) revealed AFM images of AgSb (SxSe1-x)2 that accumulated by PLD with many x-content. Table (1) demonstrates the size increase with increasing of $x$. The size is reduced with the increase of sulfur level, the size decreases from (80.34) to (63.06) nanometer if the sulfur level becomes more from (0.2) to (1). The films roughness reveals no regular variation with increasing of the sulfur level, furthermore, the surface roughness are an increase from (0.850) to (0.941) nanometer with increasing of the sulfur level from (0.2) to $(0.4)$, then decrease to $(0.681) \mathrm{nm}$ with increasing of the sulfur level.

Table.1: AFM results for AgSb (SxSe1-x)2 thin films.

\begin{tabular}{|c|c|c|}
\hline$x$ & $\begin{array}{c}\text { Average roughness } \\
(\mathrm{nm})\end{array}$ & $\begin{array}{c}\text { Average grain size } \\
(\mathrm{nm})\end{array}$ \\
\hline 0.2 & 0.850 & 80.34 \\
\hline 0.4 & 0.941 & 79.09 \\
\hline 0.8 & 0.250 & 75.40 \\
\hline 1.0 & 0.681 & 63.06 \\
\hline
\end{tabular}

December 2020, Volume 2, Issue 4

p. $48-56$ 


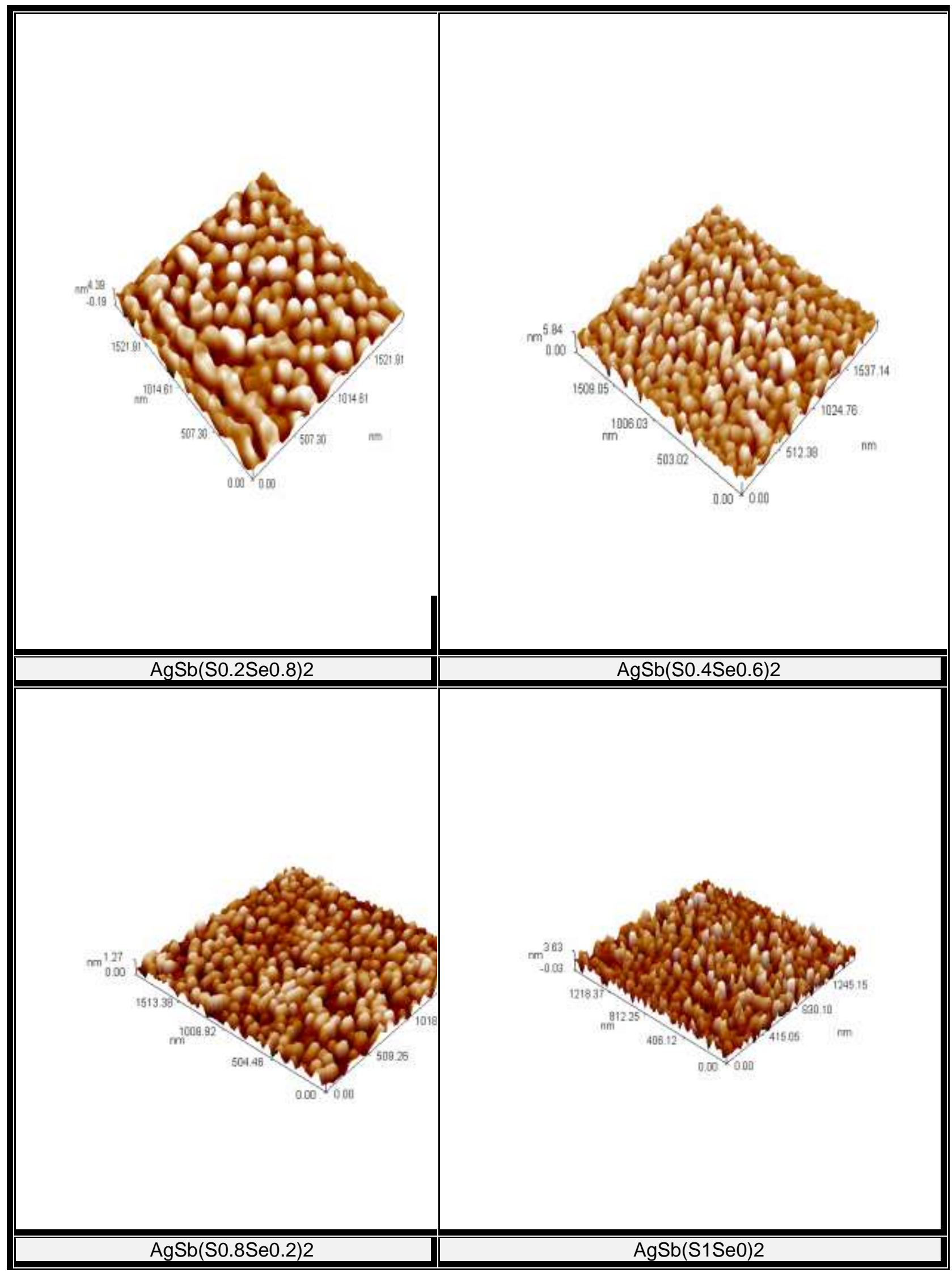

Figure.4 : 3D AFM images of AgSb (SxSe1-x)2 thin films.

December 2020, Volume 2, Issue 4

p. 48-56 
The relationship between (ahv) $1 / \mathrm{r}$ and photon energy (hv) as shown in Fig.5. The values of the optical energy gap Egopt for $\mathrm{AgSb}(\mathrm{SxSe} 1-\mathrm{x}) 2$ thin films have been Identified by extrapolation, i.e. Egopt, of the part at $\{(\mathrm{ahv}) 1 / 2=0\}[4]$. Indirect allowed where $r=0.5$ the energy gap increased from $(1.11-1.72) \mathrm{eV}$ when $\mathrm{x}$ value increase from 0.2 to 1.0. Despite of Egopt manifestation to decreases as sulfur concentration increased from 0.2 to 0 . 4. Moreover, the direct energy gap were fated throughout plotting the diagram between the variation of(ahv)2 versus the energy of the incident photon as shown in Fig. 6 and the values are paten in Table (2). It is obvious that direct Egopt variation of direct Egopt have the same direction of that of indirect one, actually it is found that Egopt decreased as Sulfur increased from 0. 2 to 0.4 but then Egopt increased from 2.22 to $2.61 \mathrm{eV}$ with the increase of sulfur concentration in from 0.4 to 1.0 .

Table.2 : Values of the optical energy gap Egopt direct and indirect

\begin{tabular}{|c|c|c|}
\hline Sample & Eg)indirect (eV) ( & Eg)direct (eV) ( \\
\hline $\mathrm{AgSb}(\mathrm{S} 0.2 \mathrm{Se} 0.8) 2$ & 1.11 & 2.31 \\
\hline $\mathrm{AgSb}(\mathrm{S} 0.4 \mathrm{Se} 0.6) 2$ & 1.05 & 2.22 \\
\hline $\mathrm{AgSb}(\mathrm{S} 0.8 \mathrm{Se} 0.2) 2$ & 1.54 & 2.50 \\
\hline $\mathrm{AgSb}(\mathrm{S} 1 \mathrm{Se} 0) 2$ & 1.72 & 2.61 \\
\hline
\end{tabular}

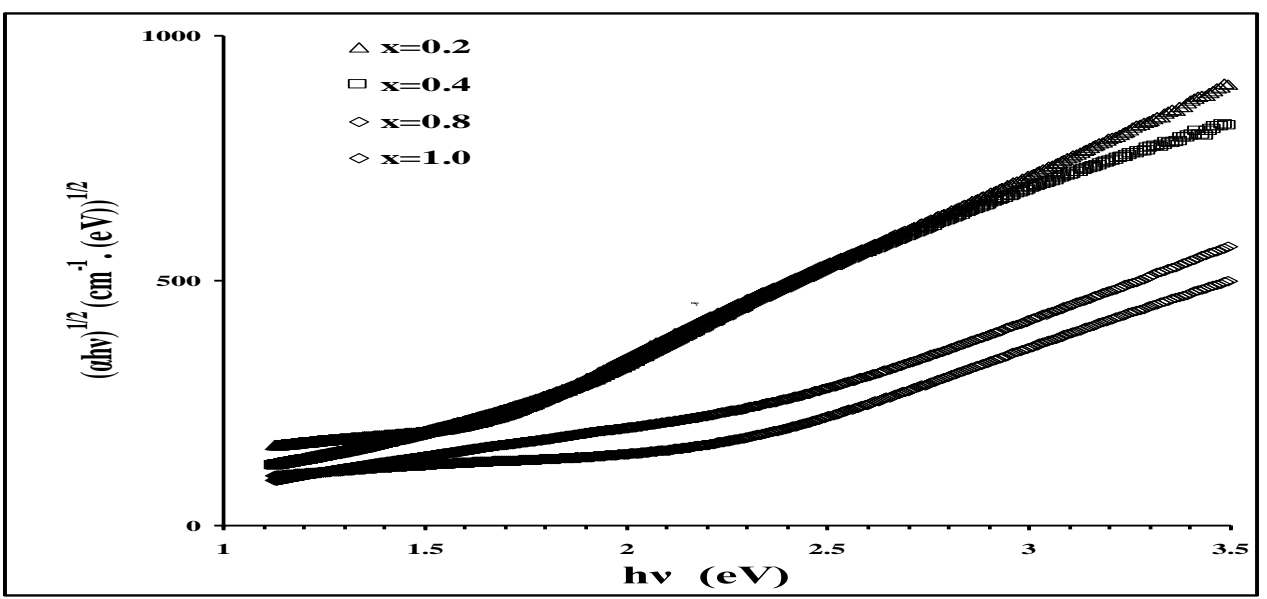

Figure.5 The relationship between (ahv)1/2oppsite (hv) of $\mathrm{AgSb}(\mathrm{SxSe} 1-\mathrm{x}) 2$ thin films with different $\mathrm{S}$ content[4].

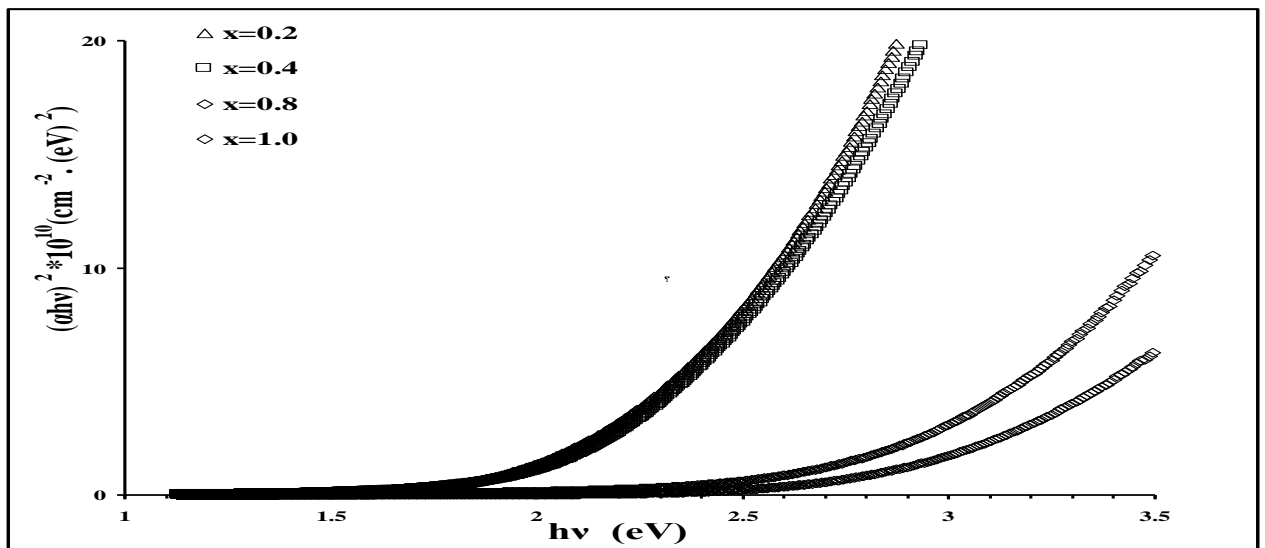

Figure.6 The relationship between (ahv)2 opposite (hv) of $\mathrm{AgSb}(\mathrm{SxSe} 1-\mathrm{x}) 2$ thin films with different $\mathrm{S}$ content[4].

The current-voltage is important parameters for measurement of the heterojunction that showed the behavior of the resultant current with its applied. Figure (7) demonstrated I-V properties of $\mathrm{AgSb}(\mathrm{SxSe} 1-\mathrm{x}) 2 / \mathrm{n}-\mathrm{Si}$ and $\mathrm{AgSb}(\mathrm{SxSe} 1-\mathrm{x}) 2 / \mathrm{p}-\mathrm{Si}$ under the dark and the light with many $\mathrm{S}$ levels $(0.2,0.4)$ for reverse and forward biasV. Figure (7) implied the current value is reduced with increased $S$ level and that occurs due to the increase of the dislocations which have an impact on the charge movement that works as active centers and the current decrease less over the junction. The current of $\mathrm{AgSb}(\mathrm{S} x \mathrm{Se} 1-\mathrm{x}) 2 / \mathrm{p}-\mathrm{Si}$ is more than $\mathrm{AgSb}(\mathrm{SxSe} 1$ - 
$\mathrm{x}$ )2/p-Si. Under the light, The I-V properties of $\mathrm{AgSb}(\mathrm{S} x \mathrm{Se} 1-\mathrm{x}) 2 / \mathrm{n}-\mathrm{Si}$ and $\mathrm{AgSb}(\mathrm{S} x \mathrm{Se} 1-\mathrm{x}) 2 / \mathrm{p}-\mathrm{Si}$ are lists in Fig. 7. The value of the current is given voltage for this apparatus at the light is more than in the dark. That means that the light absorption was done by AgSb (SxSe1-x)2 and forming carriers that take part because of the formation of the excitons and its dissociation in the free charge carriers at the barrier. The photocurrent in the apparatus in reverse orientation is enhanced by the photo. This activity used for the electron-holes that was an impact and formed in the junction by the photons. The free electrons moved to the electrodes on the barrier over the electric field at the junction. Fig.5 showed the device has photovoltaic properties at many $\mathrm{S}$ levels $(0.2$ and 0.4$)$ such as forward biasing-V. The current is increasing with increasing the voltage. That occurs due to injection at high levels of the carriers. Calculating the I-V parameters (Voc, Isc, Vmax, Imax, F.F, and $\eta$ ) are done as showed in Table (3). We note from the following table the open-circuit voltage (Voc) increase with increase the sulfur content in AgSb (SxSe1-x)2/n-Si from 0.14 to 0.41 and remain constant as the sulfur content changes in the AgSb (SxSe1-x)2/p -Si equal to 0.15 Although the sulfur content has changed, Also the short circuit current (Isc) increases with increasing sulfur(S) content from 0.2 to 0.4 in $\mathrm{AgSb}(\mathrm{SxSe1}-\mathrm{x}) 2 / \mathrm{n}-\mathrm{Si}$ and $\mathrm{AgSb}(\mathrm{SxSe1}-\mathrm{x}) 2 / \mathrm{p}-\mathrm{Si}$ heterojunction and The maximum values of the voltage $(V \max )$ when the content of $S(x=0.2)$ equals 0.12 in $\mathrm{AgSb}(\mathrm{SxSe} 1-\mathrm{x}) 2 / \mathrm{n}-\mathrm{Si}$ and keep a constant equal to 0.5 in AgSb (S0.4Se0.6)2/n-Si, (S0.2Se0.8)2/p-Si and (S0.4Se0.6)2/p-Si. The maximum values of the current Imax will remain constant in AgSb (S0.2Se0.8)2/n-Si, (S0.2Se0.8)2/p-Si, and (S0.4Se0.6)2/p-Si and equal 0.2 in (S0.4Se0.6)2/n-Si. The filling factor (F.F: The ratio of photovoltaic to its power when the current and voltage were peak [3] decreases with the increase in the sulfur content 0.2 to 0.4 in AgSb (SxSe1-x)2/n $-\mathrm{Si}$, so it decreases 0.59524 to 0.19512 , But it remains constant for all of its sulfur content $(\mathrm{x}=0.2$ and 0.4$)$ in $\mathrm{AgSb}(\mathrm{SxSe} 1-\mathrm{x}) 2 / \mathrm{p}-\mathrm{Si}$ equal to 0.13333. Overall the efficiency first for $\mathrm{AgSb}(\mathrm{SxSe} 1-\mathrm{x}) 2 / \mathrm{n}-\mathrm{Si}$ cell was decreased with increasing of the sulfur level from (0.2) to (0.4). And then equal to 0.01887 in AgSb (SxSe1$\mathrm{x}) 2 / \mathrm{p}$-Si for all sulfur content.

Table.3 I-V parameters for AgSb (SxSe1-x)2/p-Si and AgSb (SxSe1-x)2/n-Si heterojunctions showed by 106( $\mathrm{mW} / \mathrm{cm} 2$ ) with different $S$ content by white light; cell area, $0.64 \mathrm{~cm} 2$

\begin{tabular}{|c|c|c|c|c|c|c|c|}
\hline hetrojunction & \multirow{2}{*}{$\mathbf{x}$} & $V_{\text {oc }}$ & $\mathbf{I}_{\mathrm{sc}}$ & $V_{\max }$ & $I_{\max }$ & \multirow{2}{*}{ F.F } & \multirow{2}{*}{$\eta \%$} \\
\hline & & (V) & $(\mathrm{mA})$ & (V) & $(\mathrm{mA})$ & & \\
\hline $\operatorname{AgSb}\left(\mathbf{S}_{\mathrm{X}} \mathrm{Se}_{1-\mathrm{x}}\right) / \mathrm{n}-\mathrm{Si}$ & 0.2 & 0.14 & 0.12 & 0.1 & 0.1 & 0.59524 & 0.01887 \\
\hline $\operatorname{AgSb}\left(\mathrm{S}_{\mathrm{X}} \mathrm{Se}_{1-\mathrm{x}}\right) / \mathrm{n}-\mathrm{Si}$ & 0.4 & 0.41 & 0.5 & 0.2 & 0.2 & 0.19512 & 0.07547 \\
\hline $\operatorname{AgSb}\left(\mathbf{S}_{X} S_{e_{1-x}}\right) / p-S i$ & 0.2 & 0.15 & 0.5 & 0.1 & 0.1 & 0.13333 & 0.01887 \\
\hline $\mathrm{AgSb}\left(\mathrm{S}_{\mathrm{X}} \mathrm{Se}_{1-\mathrm{x}}\right) / \mathrm{p}-\mathrm{Si}$ & 0.4 & 0.15 & 0.5 & 0.1 & 0.1 & 0.13333 & 0.01887 \\
\hline
\end{tabular}

December 2020, Volume 2, Issue 4

p. 48-56 

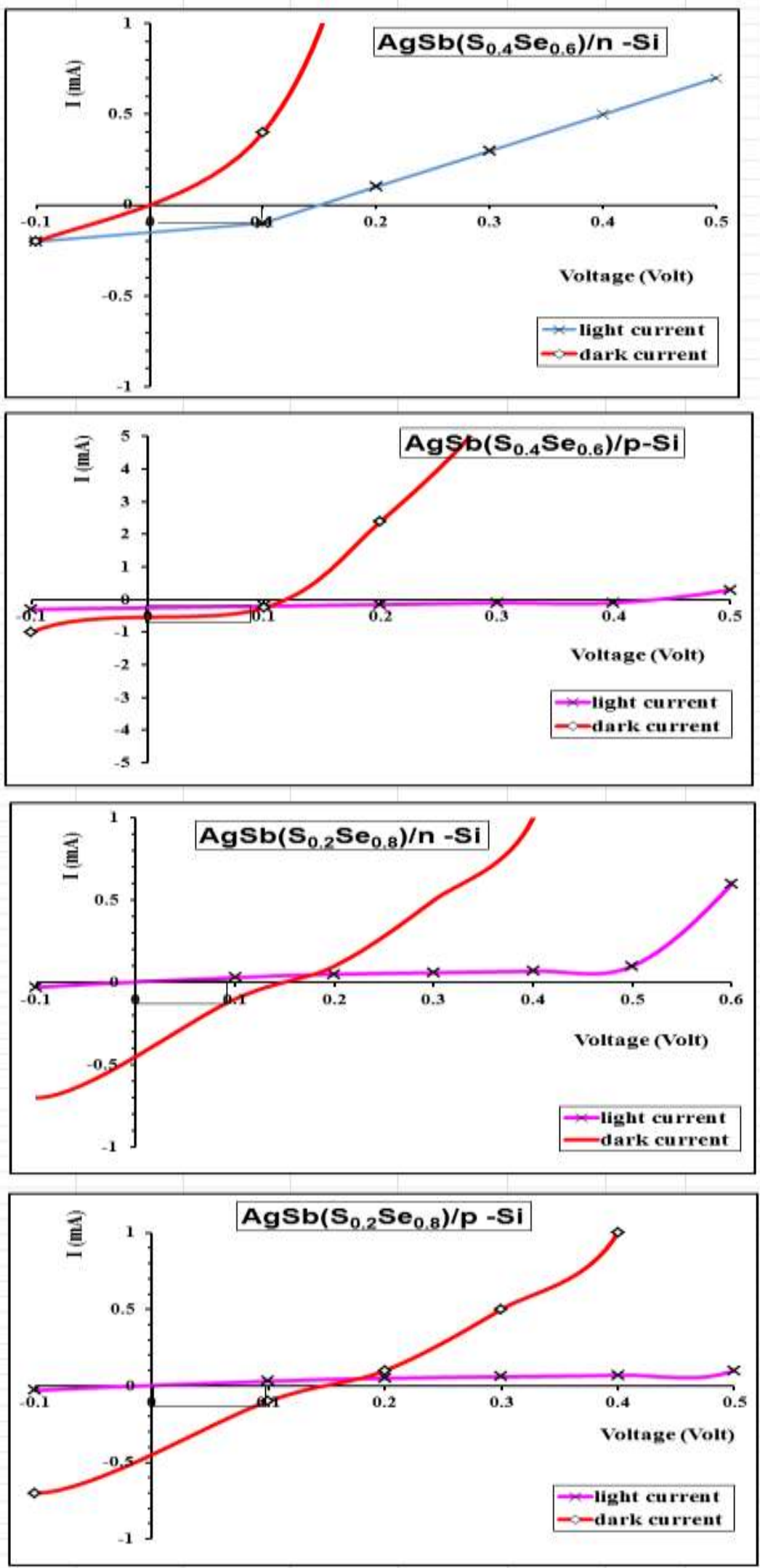

Figure.7 I-V properties for AgSb(SxSe1-x)2/p-Si and AgSb(SxSe1-x)2/n-Si heterojunctions at dark and light by $106 \mathrm{~mW} / \mathrm{cm} 2 \mathrm{with}$ different $\mathrm{S}$ content.

December 2020, Volume 2, Issue 4

p. $48-56$ 


\section{Conclusions:}

In this work, AgSb (SxSe1-x)2 thin films were prepared by heating PLD with different compositions. Many methods are used to studying the structure, shape, and optical characterizations of thin films. AgSb (SxSe1$\mathrm{x}) 2$ thin films having an indirect bandgap (Egopt) value $0.9 \mathrm{eV}$ were determined to decrease to with the increasing of the sulfur level from (0.2) to (1). The AgSb (SxSe1-x)2 thin films at RT were incorporated in PV structures as the window layers. The PV parameters were: $\mathrm{Voc}=457 \mathrm{mV}, \mathrm{Jsc}=5.87 \mathrm{~mA} / \mathrm{cm} 2$ and the conversion efficiency $(\eta)$ of $0.8 \%$ for $\mathrm{p}-\mathrm{AgSb}(\mathrm{S} 0.2 \mathrm{Se} 0.8) 2 / \mathrm{n}-\mathrm{Si}$, Voc increased to $410 \mathrm{mV}$, Jsc increased to $7.24 \mathrm{~mA} / \mathrm{cm} 2$ with conversion efficiency of $1.1 \%$ for $\mathrm{n}-\mathrm{AgSb}(\mathrm{SO} 0.4 \mathrm{Se} 0.6) 2 / \mathrm{n}-\mathrm{Si}$,

\section{References}

Anas A. ABDULLAH, Guston H. MOHAMMED and Sabri J. MOHAMMED, MINAR International Journal of Applied Scienc

Bushra A. Hasan, Hiba H.Issa. Issue 4 V(3) P(130-144), ( 2014).

Hiba H.Issa, Journal of Physics: Conf. Series P 1279 (2019) 012063.

J.G. Garza, S. Shaji, A.C. Rodriguez, T.K. Das Roy, and B. Krishnan, Appl. Surf. Sci. 257(24), P(1083410838) (2011).

J.O. González, S. Shaji, D. Avellaneda, G.A. Castillo, T.K.Das Roy, and B. Krishnan, Appl. Phys. A 116(4), P (2095- 2105) (2014). 